\title{
Editor's Note: Toward an Ethics of Gesture
}

Despite their very different contexts, the four articles in this issue of $D R J$ share a common concern with what one might call an ethics of gesture. Although the topics could not be more disparate at the level of historical location, critical approach to the material, and methodological stance for the purposes of analysis, they still ask connected questions: What sort of dance heritage can bring a better national future? (Franco); What theory of gesture can lend itself to avowed or unavowed political persuasions? (Ruprecht); How does contemporary dance practice translate a proprioceptive process of self-awareness on the dancer's part into a theatrical style with implications for dance as knowledge? (Ehrenberg); How did choreography intervene in the ethics of sexual relationships in dance theater of the 1980s? (Wittje).

Susanne Franco's "Reenacting Heritage at Bomas of Kenya: Dancing the Postcolony" in a certain sense continues the discussion of dance in the museum, which was the topic of recent special issue ( $D R J 46.3$ ) while also extending it in new directions. The Bomas of Kenya is a national heritage institution dedicated to preserving the immaterial culture of dance through the reenactment of a variety of ethnic dances by professional dancers. The ethnicities of these dancers do not always match those of the communities whose movement is being reenacted in the museum's theater. Franco's article deals at once with the projection of national identity by dance in the museum as well as the critique of such a projection by a Kenyan performance artist, Sitawa Namwalie. Throughout, issues of heritage, reenactment, idealized national identity, and authenticity as memory embodied in dance are placed in dialogue with one another against the complex background of Kenya's history and ongoing struggles for unity.

Lucia Ruprecht's article, "Gesture, Interruption, Vibration: Rethinking Early Twentieth-Century Gestural Theory and Practice in Walter Benjamin, Rudolf von Laban, and Mary Wigman," is a foray into European modernist theory of gesture. This exploration of Benjamin, Laban, and Wigman's gestural theory is an important contribution to what Ruprecht calls the "multi-faceted gestural imaginary" of modernism. One of the first studies of Benjamin, to my knowledge, that relates his thinking on gesture directly to dance, I suspect it shall not be the last. One among many of this article's striking aspects is the way it situates an aesthetics of interrupted gesture in Brechtian theater in contrast to flow in early modernist dance as aspects of "vibratory modernism" that obey differing ethical imperatives.

Shantel Ehrenberg's "A Kinesthetic Mode of Attention in Contemporary Dance Practice" is an examination of proprioceptive awareness in the contemporary dancer and the role this awareness plays both phenomenologically, stylistically, and sociologically (inasmuch as it is recognized as constituting a discourse). Ehrenberg argues for a prevailing kinesthetic awareness in contemporary dance, and situates her argument in recent approaches to phenomenology, cognition, and consciousness. She uses interview formats in order to explore the way dancers themselves experience kinesthetic self-awareness and speak of it as a form of virtuosity. Further, Ehrenberg's argument combats a "non-cognitive" dance experience by foregrounding an inquiry into dance intelligence.

(1)


Gavin Wittje's "Ethics in a Time of AIDS: DV8 Physical Theatre's Dead Dreams of Monochrome $M e n "$ is an analysis of the dance theater work by Lloyd Newson in its relation to Levinas's theory of faciality and the affect of shame. Making the claim that Dead Dreams of Monochrome Men is a response to the AIDS crisis of the 1980s, Wittje uses the film of the work to explore what constitutes an ethical relationship, and more particularly, the ethics of (gay) sex in Newson's work.

Mark Franko

Editor, $D R J$ 